\title{
PENERAPAN GRID COMPUTING UNTUK MENGKOMPILASI PROGRAM BERBAHASA C/C++
}

\author{
Yuliani Indrianingsih, Hero Wintolo, Ika Kartika Sari \\ Teknik Informatika STTA Yogyakarta \\ Informatika@stta.ac.id
}

\begin{abstract}
Grid computing is a group of computers that connected to computer network and working together to complete a certain task. The computers inside must be coheren so the processors can work evenly when given a task from server. Grid computing can be used in many areas and purpopes, and in this research it will be used to compile $\mathrm{C} / \mathrm{C}++$ program. Compilation is a process to transform a human readable source code into a computer readable code. The compilation process will take place in a personal computer (PC). By using grid system in compilation process, the waiting time of a source code will be reduced as the compilation task will be divided among the computers. For that reason a $\mathrm{C} / \mathrm{C}++$ compiler software that using grid computing will be made. The task will be distributed among the computers inside the grid. It can also help someone who want to compile $\mathrm{C} / \mathrm{C}++$ source code but he doesn't have the compiler on his PC. Keywords : grid computing, compile, $\mathrm{C} / \mathrm{C}++$
\end{abstract}

\section{PENDAHULUAN}

Grid computing merupakan suatu mekanisme pembagian tugas secara seimbang untuk membantu mempercepat waktu eksekusi suatu pekerjaan. Grid computing dapat diterapkan pada banyak bidang. Dalam penelitian ini grid computing diterapkan dalam proses kompilasi kode program berbahasa $\mathrm{C} / \mathrm{C}++$. Proses kompilasi merupakan cara untuk mengubah bahasa pemrograman yang dipahami oleh manusia menjadi bahasa yang dipahami mesin. Proses kompilasi pada umumnya dilakukan oleh compiler yang sudah dipasang pada sebuah Personal Computer (PC).Dari sinilah muncul sebuah ide untuk merancang perangkat lunak berbasis webyang diberi nama Baluran, untuk membantu proses kompilasi kode program $\mathrm{C} / \mathrm{C}++$.Perangkat lunak yang dirancang akan diterapkan dalam grid computing agar beban mengkompilasi kode program $\mathrm{C} / \mathrm{C}++$ yang diterima dapat dibagi secara seimbang sehingga mempercepat waktu kompilasi. Perangkat lunak yang dirancang memanfaatkan GNU's Not Unix (GNU) Compiler Collection (GCC) sebagai compiler.

\section{TINJAUAN PUSTAKA}


Hero Wintolo, M.Kom (2010), dalam jurnal ini menerangkan bahwa kinerja prosessor komputer client dapat dipantau dari komputer server dengan bantuan perangkat lunak yang ter-install pada komputer client.

Hero Wintolo, M.Kom (2011),dalam jurnal ini menerangkan bahwa pengeksekusian sebuah aplikasi pada komputer dapat dilakukan dengan meminjam prosessor komputer lain untuk mengeksekusinya dengan syarat dua komputer tersebut terhubung.

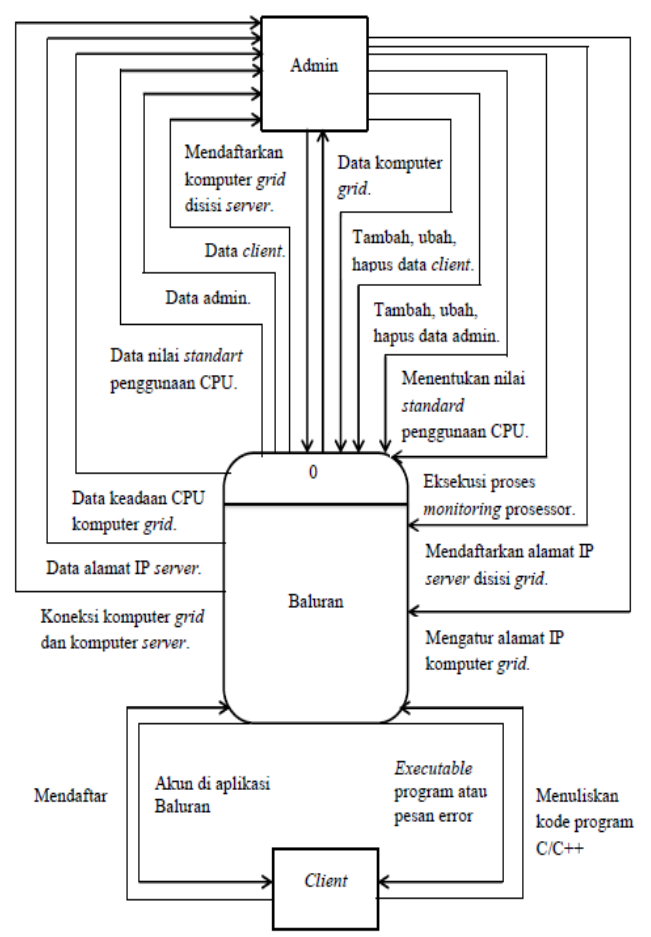

Gambar 1 Diagram konteks Baluran

\section{PERANCANGAN}

\section{Diagram Konteks Baluran}

Secara keseluruhan Baluran mempunyai dua entitas, yaitu admin dan client. Hubungan antara dua entitas tersebut terhadap Baluran seperti pada gambar 1.Berdasarkan diagram konteks diatas, tugas admin dalam Baluran adalah mendaftarkan komputer grid, memanipulasi data admin dan client jika diperlukan, menentukan nilai idle standart penggunaan CPU, mengeksekusi proses montoring CPU komputer grid, dan semua ini dilakukan pada komputer server. Sedangkan pada komputer grid, admin bertugas untuk mengatur alamat IP komputer grid dan mendaftarkan alamat IP komputer server. Beberapa informasi seperti data komputer grid, data client, data admin dan data keadaan CPU komputer grid akan didapatkan oleh admin dari pengoperasian Baluran pada sisi server. Data alamat IP server, koneksi antara komputer server dan komputer grid akan didapatkan oleh admin dari pengoperasian Baluran pada sisi grid.

Sedangkan client hanya perlu mendaftar dan menuliskan kode program $\mathrm{C} / \mathrm{C}++$ pada form yang disediakan pada Baluran. Dan Baluran akan memberikan file yang telah dikompilasi sebagai hasil dari penulisan kode program $\mathrm{C} / \mathrm{C}++$ tersebut, jika kode program yang dituliskan benar. Sedangkan jika penulisan kode programC/C++ tersebut salah maka Baluran akan memberikan pesan error. 


\section{Logical Record Structure(LRS)}

LRS dari aplikasi Baluran seperti pada gambar 2. Database yang digunakan pada Baluran mempunyai tiga tabel, yaitu tabel USERS, tabel FILE_INFO dan tabel GRID COMPUTER. Field-field pada masingmasing tabel dapat dilihat pada ERD. Tiap tabel mempunyai relasi dengan tabel yang lainnya. Tabel USERS mempunyai relasi one to many dengan tabel FILE_INFO. Field ID_USER merupakan foreign key pada tabel FILE_INFO, yang merukapan primary key pada tabel USERS. Tabel GRID_COMPUTER mempunyai relasi one to many dengan tabel FILE_INFO.

Dan Field ID_COMPUTER merupakan foreign key pada tabel FILE_INFO, yang merupakan primary key pada tabel

\section{GRID_COMPUTER.}

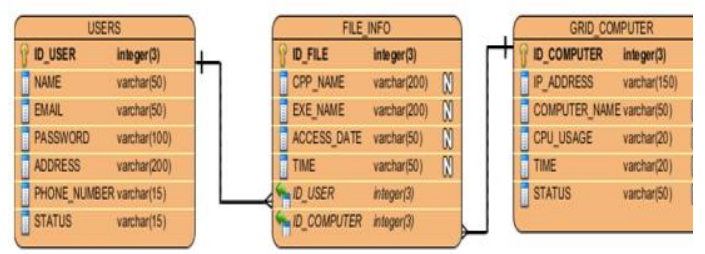

Gambar 2. LRS dari aplikasi Baluran

Keterangan simbol :

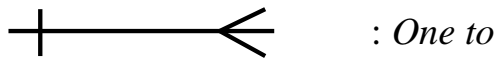

many relationship

\section{IMPLEMENTASI DAN}

\section{ANALISA}

\section{Penjelasan Aplikasi}

Aplikasi Baluran dirancang berbasis web, sehingga aplikasi ini bebas diakses oleh siapapun menggunakan platform apapun selama mempunyai kemampuan untuk membuka halaman web. Pada aplikasi Baluran terdapat dua user yaitu admin dan client. Bagian admin digunakan untuk me-manage dan manipulasi data komputer grid dan data user. Sedangkan bagian client digunakan untuk menuliskan kode program $\mathrm{C} / \mathrm{C}++$ yang akan dikompilasi.

\section{Uji Fungsi}

Pengujian fungsi Baluran dilakukan pada Laboratorium Komputasi Sekolah Tinggi Teknologi Adisutjipto (STTA). Pengujian ini dilakukan 2 kali yaitu pada jaringan lokal dan pada jaringan internet. Pengujian pada jaringan lokal membutuhkan 13 komputer, dengan rincian 10 komputer grid, 1 komputer server dan 2 komputer client. Semua komputer-komputer tersebut terkoneksi dalam satu jaringan komputer. Skema jaringan pada pengujian jaringan lokal lengkap dengan alamat IP tiap computer seperti pada gambar 3 . 


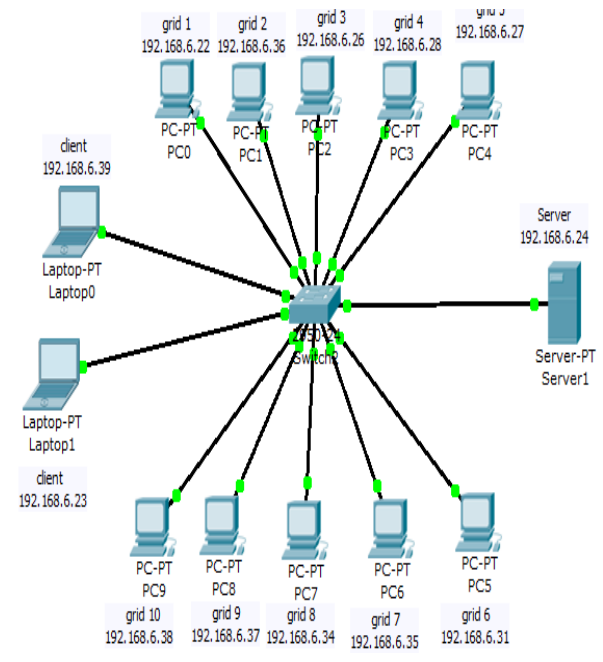

\section{Gambar 3 Skema jaringan pada pengujian jaringan lokal}

Sedangkan pada pengujian fungsi Baluran pada jaringan internet dibutuhkan 4 komputer dan 4 modem. Dengan rincian 2 komputer dan 2 modem untuk komputer grid, 1 komputer dan 1 modem untuk komputer server, 1 komputer dan 1 modem untuk client. Modem yang dipakai dalam pengujian ini adalah modem ZTE MF 180 dengan kecepatan up to $3.6 \mathrm{Mbps}$, HUAWEI E303 dengan kecepatan up to 7.2 Mbps, HUAWEI E173 dengan kecepatan up to $7.2 \mathrm{Mbps}$, HUAWEI K3520 dengan kecepatan 3.6 Mbps. Keempat modem tersebut menggunakan Subscriber Identity Module (SIM) card IM3 dari provider Indosat dengan kecepatan up to 7.2 Mbps. Skema jaringan pengujian jaringan internet seperti pada gambar 4 .

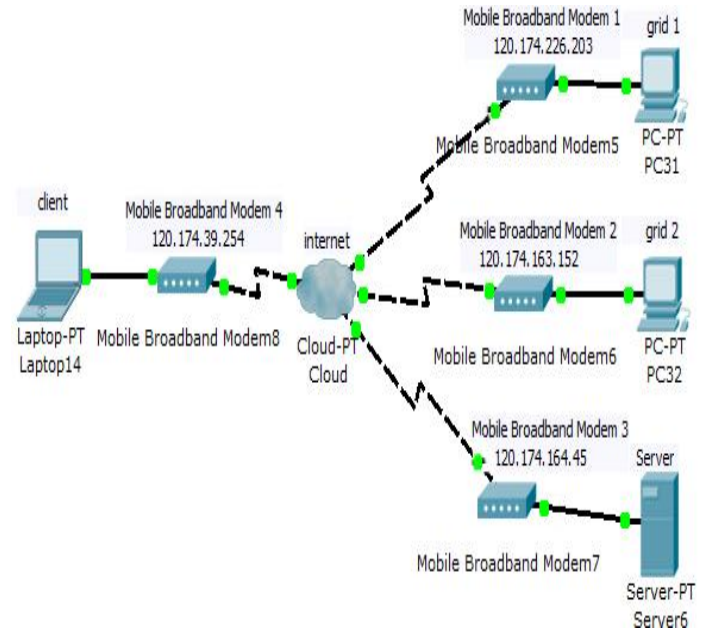

\section{Gambar 4 Skema jaringan pada pengujian jaringan internet}

Pengujiaan Baluran akan dilakukan dengan mensimulasikan beberapa keadaan. Mengkompilasi kode program $\mathrm{C} / \mathrm{C}++$ untuk mendapatkan keadaan yang benar. Dan mengkompilasi kode program java untuk mendapatkan keadaan yang salah.

\section{Analisa Uji Fungsi Pada Jaringan Lokal}

Pelaksanaan pengujian pada jaringan lokal yang pertama dilakukan dengan mengkompilasi kode program $\mathrm{C}$. Salah satu kode program C yang akan dikompilasi adalah sebagai berikut :

1. \# include <stdio.h>

2. $\operatorname{main}()\{$ int $a, b, c, \max , \min$;

3. printf("Masukan bil 1 : ");scanf("\%d",\&a);

4. printf("Masukan bil 2 : ");scanf("\%d",\&b);

5. printf("Masukan bil 3 : ");scanf("\%d",\&c);

6. if $(a>b)\{\max =a ; \min =b ;\}$

7. else $\{\max =b ; \min =a ;\}$

8. if $(c>\max ) \max =c$; 
9. if $(\mathrm{c}<\min ) \min =c$;

10. printf("Maka bilangan terbesar adalah \%d\n",max);

11. printf("Maka bilangan terkecil adalah \%d",min);

Download The Result Of Your Code In Here...

Executable file : 211.07-2013_13-18-16_lexe

$\mathrm{CC}+$ file : 211.07.2013.13.18-16_...9p

elapsed time : 0.655747909459 seconds

Thank You...

Chick here For Back To Home

\section{Gambar 5 Hasil kompilasi kode} program C

Pada hasil kompilasi, nama file executable dan file kode program dibuatkan oleh aplikasi baluran yang merupakan kombinasi dari beberapa data file tersebut. Sebagai contoh nama fileseperti pada gambar 5 yaitu 2_11-072013_13-18-16_1.exe dan 2_11-072013_13-18-16_1.cpp. Nama tersebut merupakan kombinasi dari id user client yaitu 2, tanggal file dikompilasi yaitu 11-07-2013, waktu file dikompilasi yaitu pukul 13:18:16, dan id komputer grid yang mengkompilasi file tersebut yaitu 1. Hal ini dilakukan agar file client tidak tertukar dengan file client yang lain. Selain itu waktu tunggu proses kompilasi juga ditampilkan, seperti pada gambar 5. Waktu tunggu ini dihitung mulai saat client meng-click tombol Compile pada halaman home sampai link untuk mengunduh file executable dan kode program muncul. Pada file $\mathrm{C}$ ini misalnya waktu tunggu proses kompilasi adalah 0.6357479095459 detik. Ukuran file executable yang dihasilkan dari kompilasi kode program $\mathrm{C}$ ini adalah $21 \mathrm{~KB}$ dan ukuran file yang berisi kode program yang dihasilkan adalah $1 \mathrm{~KB}$.

Pelaksanaan pengujian pada jaringan lokal yang terakhir dilakukan dengan mengkompilasi kode program java. Salah satu kode program java yang akan dikompilasi sebagai berikut :

1. package javaapplication8;

2. import javax.swing.JOptionPane;

3. public class JavaApplication8\{

4. public static void main(String[]args) \{

5. int a,b,bayar; double harga,diskon,f; $\quad$ String bil1,bil2,bil3,bil4;

6. bil3=JOptionPane.showInputDialo $\mathrm{g}$ ("Berapa besaran diskon $[10 \%=0.1] ")$;

7. diskon=Double.parseDouble(bil3) ;

8. bill=JOptionPane.showInputDialo g("Berapa jumlah RAM yang anda beli");

9. $a=$ Integer.parseInt(bil1);

10. bil2=JOptionPane.showInputDialo g("Berapa kapasitas RAM yang anda beli [ $1 \mathrm{~Gb}$ atau $2 \mathrm{~Gb}] ")$;

11. $b=$ Integer.parseInt(bil2);

12. $\operatorname{if}(\mathrm{a}>=2)\{$

13. $\mathrm{if}(\mathrm{b}==1)\{$

14. $\operatorname{harga}=\left(a^{*} 150000\right)$ $(\mathrm{a} *(150000 *$ diskon $))$; 
15. JOptionPane.showMessageDialog (null, "Harga yang harus dibayar "+harga);

16. bil4=JOptionPane.showInputDialo g("Jumlah uang anda ");

17. bayar=Integer.parseInt(bil4);

18. f=bayar-harga;

19. JOptionPane.showMessageDialog (null,"Uang kembaliannya " +f); \}

20. else \{

21. harga $=\mathrm{a} * 250000$;

22. JOptionPane.showMessageDialog (null, "Maaf anda tidak mendapatkan diskon dan harus membayar sebesar "+harga);

23. bil4=JOptionPane.showInputDialo g("Jumlah uang anda ");

24. bayar=Integer.parseInt(bil4);

25. f=bayar-harga;

26. JOptionPane.showMessageDialog (null, "Kembaliannya "+f);\} \}

27. else \{

28. if $(b==1)\{\quad$ harga $=a * 150000$;

29. JOptionPane.showMessageDialog (null, "Maaf anda tidak mendapatkan diskon dan harus membayar sebesar "+harga);

30. bil4=JOptionPane.showInputDialo g("Jumlah uang anda ");

31. bayar=Integer.parseInt(bil4);

32. $\mathrm{f}=$ bayar-harga;

33. JOptionPane.showMessageDialog (null, "Kembaliannya "+f); \}

34. else \{

35. harga $=\mathrm{a} * 250000$;

36. JOptionPane.showMessageDialog (null, "Maaf anda tidak mendapatkan diskon dan harus membayar sebesar "+harga);

37.

bil4=JOptionPane.showInputDialo g("Jumlah uang anda ");

38. bayar=Integer.parseInt(bil4);f=bay ar-harga;

39. JOptionPane.showMessageDialog (null, "Kembaliannya "+f); \}\} \} \}

\section{Download The Result Of Your Code In Here...}

Message Error..

3_11-07-2013_13-414-32_1.cpp:60:2 : warning: no

newline at end of 11 is

311-07-2013_13-44-32 1.0pp:1: exror: 'package' doeo

not narre a type

13-44-32 1.cpp: 2: error: 'import' does

3. 11-07-2013 13-44-32 1, epp:3: exror: expected

unqualified-id before ${ }^{-}$public:

$$
\mathrm{C} / \mathrm{C}++ \text { file : } 3 \_11-07-2013 \_13-44-32 \_1 . \mathrm{cpD}
$$

elapsed time : $0.58773493766785 \quad$ seconds

Thank You....

Click Here For Back To Home

Gambar 6 Hasil kompilasi kode program java

Nama file kode program hasil kompilasi kode program java ini adalah 3_11-07-2013_13-44-32_1.cpp. Nama tersebut merupakan kombinasi dari id user client yaitu 3, tanggal file dikompilasi yaitu 11-07-2013, waktu file dikompilasi yaitu pukul 13:44:32, dan id komputer grid yang mengkompilasi file tersebut yaitu 1. Waktu tunggu proses kompilasi kode program java ini adalah 0.58773493766785 detik. Ukuran file yang berisi kode program yang dihasilkan adalah 3 KB.Dari hasil pengujian fungsi pada jaringan lokal maka dapat dilihat bahwa aplikasi Baluran dapat mengkompilasi program $\mathrm{C} / \mathrm{C}++$ dan dapat memilihkan komputer grid yang tepat untuk mengkompilasi kode program. 


\section{AnalisaUji Fungsi Pada Jaringan \\ Internet}

Pengujian pada jaringan internet dilakukan dengan mengkompilasi kode program $\mathrm{C} / \mathrm{C}++$ dan java yang sama dengan kode program yang dikompilasi saat pengujian pada jaringan lokal. Pengujian yang pertama dengan mengkompilasi kode program $\mathrm{C}$ dan hasil kompilasi seperti pada gambar 7 .

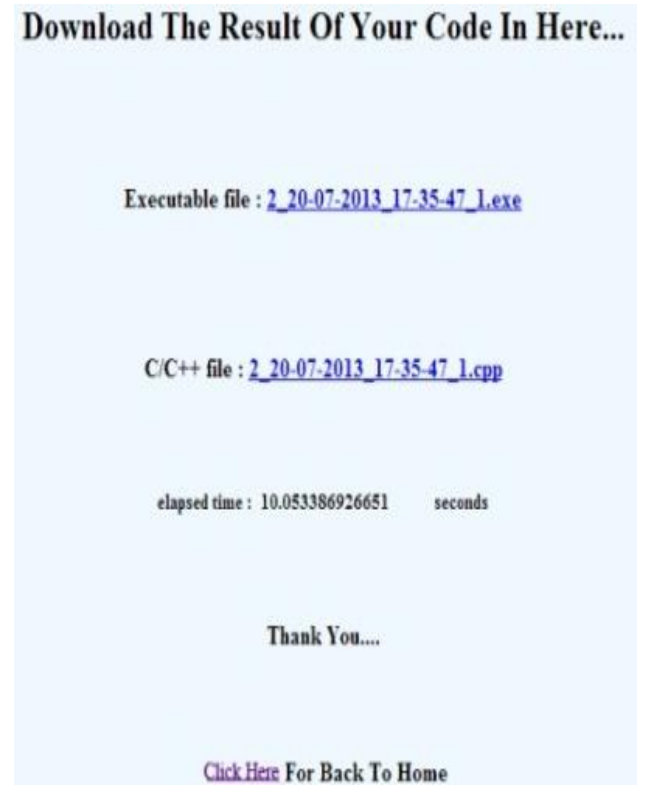

Gambar 7 Hasil kompilasi kode program $\mathrm{C}$ pada pengujian internet

Nama file executable dan file kode program hasil kompilasi kode program C ini adalah 2_20-07-2013_1735-47_1.exe dan 2_20-07-2013_17-3547_1.cpp. Nama tersebut merupakan kombinasi dari id user client yaitu 2, tanggal file dikompilasi yaitu 20-072013, waktu file dikompilasi yaitu pukul 17:35:47, dan id komputer grid yang mengkompilasi file tersebut yaitu 2 . Waktu tunggu proses kompilasi kode program C ini adalah 10.053386926651 detik. Ukuran file executable yang dihasilkan dari kompilasi kode program $\mathrm{C}$ ini adalah $21 \mathrm{~KB}$ dan ukuran file yang berisi kode program yang dihasilkan adalah $1 \mathrm{~KB}$.

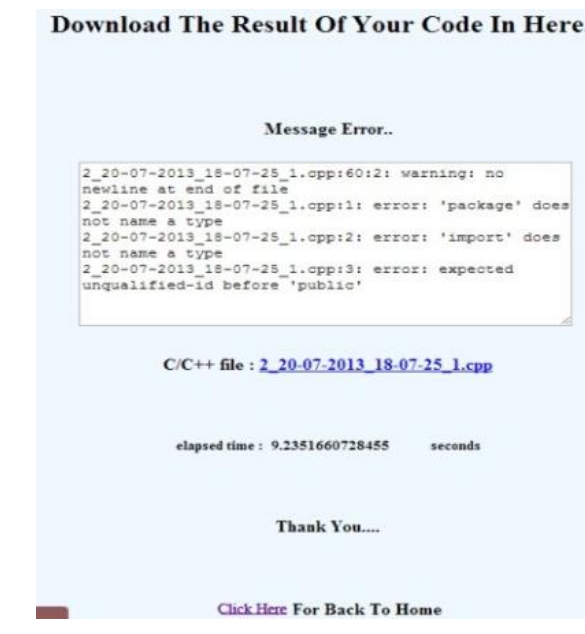

Gambar 8 Hasil kompilasi kode program java pada pengujian internet

Kemudian dilanjutkan dengan mengkompilasi kode program java. Hasil kompilasi kode program seperti pada gambar 8. Nama file executable dan file kode program hasil kompilasi kode program $\mathrm{C}++$ ini adalah 2_20-072013_18-07-25_1.exe dan 2_20-072013_18-07-25_1.cpp. Nama tersebut merupakan kombinasi dari id user client yaitu 2, tanggal file dikompilasi yaitu 20-07-2013, waktu file dikompilasi yaitu pukul 18:07:25, dan id komputer grid yang mengkompilasi file tersebut yaitu 1. Waktu tunggu proses kompilasi kode 
program java ini adalah 9.2351660728455 detik. Ukuran file yang berisi kode program yang dihasilkan adalah $3 \mathrm{~KB}$.

Dari hasil pengujian fungsi pada jaringan internet maka dapat dilihat bahwa waktu tunggu proses kompilasi kode program pada jaringan internet lebih lama daripada waktu tunggu proses kompilasi kode program pada jaringan lokal. Dari hasil pengujian fungsi pada jaringan internet dan pada jaringan lokal dapat dilihat pula bahwa waktu tunggu proses kompilasi dengan kode program yang benar lebih lama daripada proses kompilasi dengan kode program yang salah. Hal ini terjadi karena saat proses kompilasi dengan kode program salah, compiler tidak perlu membuat file executable lagi dan hanya perlu menampilkan pesan error.

\section{KESIMPULAN DAN SARAN}

\section{Kesimpulan}

Setelah melalui tahapan pengujian aplikasi, maka dapat disimpulkan :

1. Perangkat lunak hasil rancangan yang diberi nama Baluran, dapat diterapkan pada grid computing.

2. Kompilasi dapat dilakukan dengan memanfaatkan jaringan komputer lokal atau yang biasa disebut dengan LAN dan jaringan internet.
3. Compiler GCC dapat digunakan untuk mengkompilasi kode program $\mathrm{C} / \mathrm{C}++$ yang dikirimkan dari jarak jauh.

4. Dari hasil pengisian kuesioner oleh para responden, maka dapat disimpulkan bahwa Baluran merupakan aplikasi yang layak digunakan.

\section{Saran}

Setelah melalui tahapan pengujian aplikasi, maka saran yang dapat disampaikan untuk membantu pengembangan aplikasi ini sebagai berikut:

1. Jika Baluran akan diterapkan pada jaringan internet, disarankan memakai alamat IP public yang statis.

2. Aplikasi Baluran dapat dikembangkan lagi dengan penambahan mekanisme load balancing didalamnya.

\section{DAFTAR PUSTAKA}

Clement Salome, Pottle Brian, Singh, Oracle Database : $S Q L$ Fundamentals I, Oracle, Edition 1.0, 2010.

Hari Soetanto, Teknik Kompilasi, Fakultas Teknologi Informasi Universitas Budi Luhur, 2004.

Hero Wintolo, Deteksi Kinerja Prosesor komputer client dengan cara remote untuk mendukung aplikasi pemrosesan parallel, Sekolah 
Tinggi Teknologi Adisutjipto Yogyakarta, Volume 2, 2010.

Hero Wintolo, Design of Parallel Processing applications With The Remote Execution, Sekolah Tinggi Teknologi Adisutjipto Yogyakarta, Volume III, 2011.

Jogiyanto, Analisis \& Desain, Sistem Informasi : Pendekatan Terstruktur Teori Dan Praktik Aplikasi Bisnis, ANDI OFFSET, Edisi III, 2005.

Raharjo Budi, Belajar Otodidak Pemrograman Web Dengan PHP + Oracle, Informatika, 2011.

Wilikison Barry \& Allen Michael, Parallel Programming, ANDI OFFSET, 2010.

http://www.databasedesign.co.uk/bookd atabasesafirstcourse/chap3/chap3.ht m, diakses pada tanggal 29 Juli 2013.

http://data.bangtech.com/datamodel/visi o_chen_erd.htm, diakses pada tanggal 29 Juli 2013.

http://albahrimaraxsa.wordpress.com/2 012/05/01/erd-lrs-dan-relasi/, diakses pada tanggal 29 Juli 2013.

http://www.w3schools.com/, diakses pada tanggal 29 Juli 2013.

http://getbootstrap.com/, diakses pada tanggal 29 Juli 2013.

http://php.net/manual/en/, diakses pada tanggal 29 Juli 2013.

http://computer.howstuffworks.com/, diakses pada tanggal 29 Juli 2013.

http://www.techonthenet.com/oracle/, diakses pada tanggal 29 Juli 2013. 